\title{
Francesco Guicciardini: Diálogo sobre el gobierno de Florencia. Madrid: Akal, 2017, 266 pp.
}

\section{Jerónimo Ríos Sierra \\ Universidad Complutense de Madrid (España)}

Hablar de Francesco Guicciardini (1483-1540) es hacer referencia a uno de los grandes jurisconsultos florentinos de inicios del siglo XVI. De sus primeros trabajos escritos se pueden destacar, entre otros, las Storie Florentine, iniciadas en 1508 pero publicadas en la segunda mitad del siglo XIX, en las que critica ferozmente a personalidades como Lorenzo de Medici o Girolamo Savonarola y defiende con rotundidad su primera noción de gobierno ideal, erigido desde el conocimiento y la sabiduría.

Desde entonces, Guicciardini imbrica una muy activa vida política con una prolija actividad teórica e intelectual. De la primera, cabe destacar que fue embajador florentino en España, gobernador de Módena (1516), gobernador de Reggio Emilia y Parma (1517) y que en 1521 se desempeñó como comisario general del ejército pontificio, aliado de Carlos V en la guerra contra Francia, y de cuya experiencia escribirá en obras de obligada referencia como los Ricordi politici e civili o Storia d'Italia.

Desde 1526 su vida política pasa a ser mucho más agitada, por el cometido de tratar de mantener un cierto grado de cohesión en una península itálica tan convulsa como azotada por las enemistades y las fracturas políticas. Lo anterior, unido a su cercanía a los Medici, a la ruptura del Acuerdo de Cognac (1426), al saqueo de Roma por cuenta de lansquenetes o a la instauración, por tercera vez, de la república en Florencia, le llevan a retirarse a su villa en Finochietto. Será allí, precisamente, donde escribirá las Considerazioni intorno ai «Discorsi» del Machiavelli «sopra la prima deca di Tito Livio» -refutando las tesis planteadas por Maquiavelo-, y donde quedará relegado del poder y confiscado de sus bienes en 1529. Razón por la que marchará a Bolonia, en calidad de asesor de Clemente VII en 1529, y dos años después, con el regreso de los Medici a Florencia, volverá a la misma para aconsejar al Duque Alejandro. Su sucesor, Cosme I, prescindirá rápidamente del apoyo de Guicciardini, lo cual le lleva a retirarse, ya en sus últimos años, a su villa 
en Arcetri, lugar en donde reescribirá y ordenará los Ricordi y culminará su gran Storia d'Italia.

El pensamiento político de Guicciardini gravita fundamentalmente en torno al análisis historiográfico de la península itálica, entre 1494 y 1532, lo cual le convierte en protagonista de la gran generación de pensadores florentinos de la época, no solo junto a Maquiavelo, sino con otros como Segni, Vettori o Giannotti. Su trabajo por desenmarañar la intricada red de nexos políticos de la vida italiana tiene como gran valor agregado la distante posición imparcial que adopta. Por ejemplo, mientras que Maquiavelo defiende el unitarismo italiano -imposible por la intromisión del Papado-, para Guicciardini la poliarquía republicana garantiza estabilidad y orden, siendo lo que alimenta el florecimiento cultural del Renacimiento, a falta de una fórmula federal idónea.

Lo cierto es que con Guicciardini cabe afirmar que existe una impronta de realismo que supera a la del mismo Maquiavelo, cuyo afán por emular a las grandes naciones unitarias europeas le lleva a pasar por alto el factor aglutinador que al respecto supuso la emergencia de una burguesía pudiente, creciente y abierta, inexistente en Italia y fuertemente criticada por Guicciardini.

Además del texto en sí objeto de reflexión, hay que reconocer que ante nosotros tenemos igualmente una excelente, pulcra y cuidadísima traducción primera al español- del profesor de la Universidad de Sevilla Antonio Hermosa Andújar, cuyo prólogo disecciona a la perfección, con un lenguaje tan nítido como envolvente, algunos de los conceptos e ideas clave del Diálogo sobre el Gobierno de Florencia (1527), como son el nuevo orden político, la noción de República, o los valores de igualdad, justicia o legitimidad.

Formalmente, y más allá del estudio preliminar, la obra se estructura en tres partes claramente diferenciadas: un proemio inicial y dos libros que conducen al lector a una suerte de diálogo platónico en el que la cuestión central no es otra que hacer de Florencia un gobierno recto, legítimo e inspirado en la idea misma de libertad y experiencia.

Como bien señala el profesor Hermosa (p. 7), el punto de partida para entender la posición teórica del Diálogo es la autonomía de la política, el poder de la sabiduría y el valor de la experiencia. Es como si se inscribiera el momento político en una suerte de continuum en el que lo ocurrido y lo que está por suceder han de ser resueltos, en cada momento, por el oficio del político, pues a él le corresponde identificar las lecciones aprendidas, los acontecimientos irrepetibles y el saber dirigir el timón del gobierno con la necesaria decisión correcta. Verdad, corrección y conocimiento, en suma, son el trinomio indisociable que ha de prevalecer en cada acto de gobierno ejemplar.

Por otro lado, para Guicciardini, y en oposición a Maquiavelo, es necesario huir de las formas de gobierno puras, de manera que es mejor optar por formas mixtas que velen por la libertad como bien jurídico supremo; algo que no 
"significa más que justicia e igualdad" y "algún modo eficaz de reprimir a quien maquinase contra el Estado" (p. 182). Tal y como se recoge con fuerza en el segundo libro segundo, la clave de todo reposa en la experiencia: "De ahí que no hayamos de ir en búsqueda de un gobierno soñado y más fácil de encontrar en los libros que en la realidad (...) y éste sea de acuerdo a la naturaleza, las características, las condiciones, las inclinaciones, o por encerrar todo eso en un solo nombre, los humores de la ciudad y de los ciudadanos" (p. 178).

Ya en sí, la forma de diálogo en la que transcurre el texto se presenta al más estricto modo platónico, de una manera ágil y dinámica para el lector, y con base en cuatro personajes. Por un lado, se encuentra Bernardo del Nero, que es el alter ego de Guicciardini y que, vinculado con el partido mediceo, se encarga de controvertir con los otros tres, especialmente, a efectos de cuestionar y deconstruir el dogmatismo republicano y mostrar el pavor que le representa el gobierno del pueblo -al que concibe como profundamente incapaz de saber de la cosa pública-. Así, los otros tres personajes, contradictores del florentino, son Piero Guicciardini - que en muchas ocasiones pudiera entenderse como el alter ego de Maquiavelo-, Paolantonio Soderini -gonfaloniero vitalicio de Florencia- y Piero Capponi -defensor del republicanismo de corte aristocrático-. Asimismo, conviene precisar que toda la discusión sobre cuál debe ser la forma de gobernar Florencia frente a la que se articula el texto se inscribe en 1494, año de gran agitación en la vida florentina por traer consigo el paso del principado a la forma republicana con el ascenso al poder de Girolamo Savonarola.

Volviendo a la idea del gobierno ideal, frente a las reflexiones sobre la anaciclosis o sobre la evolución de las formas de gobierno, a la manera de Polibio o, antes, en Aristóteles, hasta la revisión de Maquiavelo, Guicciardini prefiere el gobierno monocrático, porque "cuando es bueno, es el mejor de todos; y se le llama bueno, cuando de manera voluntaria es antepuesto a los demás quien es más apto a gobernar" (p. 175). De este modo, y sin perder de vista la importancia de razón, experiencia y práctica, puestos a elegir vendría después el gobierno de unos pocos, aunque lo entiende como impracticable en Florencia a tenor de las disidencias excluyentes en torno al poder. Finalmente, el más indeseable, por oponerse al sentido de estos tres valores, sería el gobierno del pueblo, por ser el más errante e incapaz, pero no tanto por una reflexión teorizada de las bondades o maldades de cada uno sino, más sencillo, por el escaso uso racional de la experiencia y su factibilidad que conlleva.

El sentido práctico de Guicciardini queda patente en una de sus grandes preocupaciones: la de entender la rectitud del gobierno como el respeto a las leyes, las instituciones, el sentido de libertad y justicia y la salvaguarda del interés común. Interés, por cierto, garantizado por la presencia de un Gran 
Consejo que representa al pueblo - de ahí el sentido mixto del gobierno- y asegure la meritocracia a la hora de participar en los asuntos públicos, limitando el ejercicio del poder y promoviendo los valores de igualdad y justicia (p. 38; p. 182).

Ahora bien, como señala en el estudio preliminar el profesor Hermosa, frente a lo anterior cabe plantearse una pregunta: “¿cómo se garantiza Guicciardini de la usurpación de carácter popular de la república y su reemplazo por otro aristocrático, una vez sancionado el derecho de los mejores a gobernar y establecido ese cursus honorum en el que en la práctica el mérito va tomando forma?" (p. 26). Solo es posible con una estructura orgánica, institucional, meritocrática organizada bajo criterios de selección y decisión, y sobre la base de relaciones de poder claramente definidas, pues "el secreto del buen gobierno se revela todo él ahí. Es la llave de la seguridad de personas y bienes, por un lado, y de la prosperidad de la ciudad, junto a la unión de sus habitantes, por otro" (p. 20).

En algunas ocasiones a Guicciardini se le puede malinterpretar, entendiendo que su recelo omnipresente a la participación del pueblo en los asuntos públicos casa con un elitismo burócrata que entiende el gobierno del común como una suerte de tiranía irreflexiva de las masas -expresión traída al uso de Madison en The Federalist Papers-. Todo lo contrario, una conditio sine qua non del buen gobierno, del gobierno recto, exige que el pueblo gestione y se involucre en los asuntos públicos, mas con los frenos y criterios que continuamente se preocupa por delimitar en los Diálogos y que le convierten en valedor de una forma mixta de gobierno.

Un último elemento a destacar, de los muchos que se podrían en un libro como éste, es el perfecto contraste que se pone de manifiesto entre los libros 1 y 2. Lo anterior, porque si bien el modelo de gobierno ideal para Florencia es especialmente abordado en el segundo de los libros, en el primero de ellos Guicciardini parece incurrir en cierta contradicción al presentar como modélico un régimen tiránico como es el personificado en los Medici. Nuevamente conviene no perder de vista el realismo político del pensador florentino y su alto nivel de pragmatismo: la violencia es indisociable de la noción de Estado y de poder y, pese a todo, el hombre es valorado negativamente desde un punto de vista antropológico. Realismo y dinamismo son, por ende, atributos ausentes en las formas puras de gobierno, precisamente, por estar éstas limitadas por un carácter estanco y excluyente. Sensu contrario, solo el gobierno mixto sería el capaz de adaptarse a las particularidades del momento, sin perder de vista la experiencia del pasado.

Por todo ello, nos encontramos ante una obra maestra del Renacimiento italiano que indaga y se preocupa sobre aspectos nucleares del pensamiento político como son el poder, el Estado, el buen gobierno o la legitimidad. 
Guicciardini siempre ha quedado relegado a una especie de ostracismo en el estudio del pensamiento político por la excesiva atención que concentra Maquiavelo. Sin embargo, leer y problematizar a Guicciardini, además de imprescindible, no hace sino ofrecer nuevas miradas para entender al autor de El Príncipe. En cualquier caso, no se pierdan el estudio preliminar que realiza el profesor Antonio Hermosa sobre el texto pues, sin duda, implica un altísimo valor agregado para una obra de referencia excelentemente tratada y mejor traducida. 
